\title{
Escritos sobre Picasso (1921-1946)
}

\author{
WALDEMAR-GEORGE \\ Edición bilingüe a cargo de Carlos Ferrer Barrera, Fundación Picasso, Museo Casa Natal, 2017
}

Las tareas de compilación, traducción y, en última instancia y no menos importante, edición son acciones tan reseñables como la propia escritura. La comunicación de ideas, con las que se puede estar de acuerdo o no, es una valiosa iniciativa para generar debate. Esto es lo que viene haciendo la Fundación Picasso. Museo Casa Natal con su colección de Textos Recuperables que comenzó en 2013. Ahora, cuatro años después, edita su cuarto volumen en edición bilingüe a cargo del doctor en historia del arte y especialista en la iconografía picassiana Carlos Ferrer.

Ferrer edita y prologa una selección de textos inéditos en español convirtiéndose con ello en una destacable aportación a la bibliografía picassiana y llegando a estar incluido en la lista de Antonio Javier López (Diario Sur) de «libros imprescindibles» editados en Málaga en 2017. En él se recogen dos monografías y ocho artículos salidos de la pluma de Waldemar-George (1893-1970) con sus correspondientes originales. El crítico más comprometido e intransigente del pasado siglo trata la figura de Picasso como principal protagonista, pero dejando traslucir con ello sus propias ideas estéticas y su pensamiento poliédrico. La justa selección de escritos aborda una línea cronológica (1921-1946) en la que el autor de ellos cambió y viró su opinión progresivamente. A través de él podemos seguir la senda artística que el propio Picasso iba desarrollando, las etapas por las que pasaba y los estilos artísticos que abordaba.

Las dos décadas que se recogen en este libro muestran el pensamiento de Waldemar-George desde su crítica más acérrima hacia las creaciones de Picasso hasta su completa defenestración. El primer texto de Waldemar-George con que se inaugura esta edición es una monografía publicada en 1924 y titulada precisamente Pablo Picasso. Este texto quizá sea uno de los más cercanos a la admiración por el artista, situándolo en el último eslabón de la cadena evolutiva de la pintura moderna con sentencias tan lapidarias como «Picasso restituye a la pintura contemporánea francesa ese elemento manual y tangible del que la habían despo-

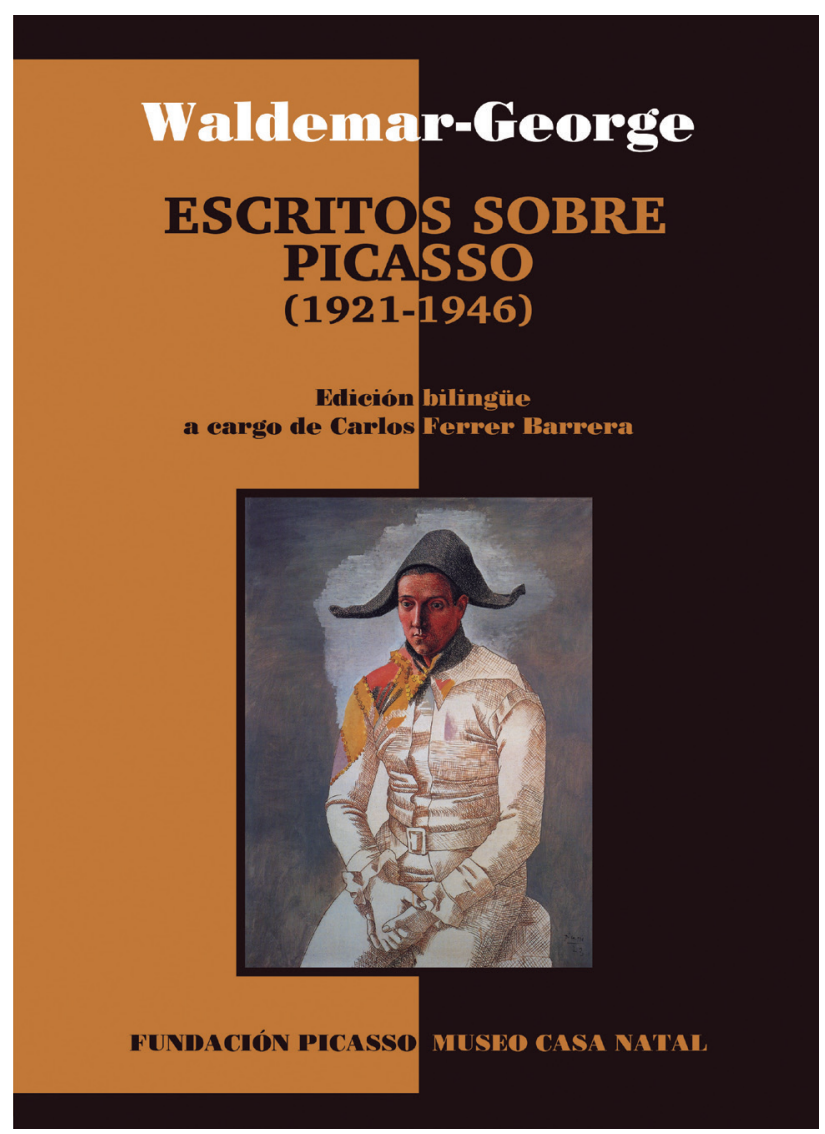

jado Delacroix y los impresionistas». Aquí el autor considera que Picasso está siguiendo la senda de la pintura moderna y desembocará en lo que estima que es el curso natural de un movimiento o estilo pictórico, es decir, que llegará al culmen de la pintura cubista. El análisis formal que hace de las creaciones es certero y la consideración de Picasso como artesano no es menos válida; Picasso como hacedor, demiurgo.

Dos años después publica la segunda monografía que aquí se recoge titulada Picasso. Dibujos y editada por Éditions des Quatre Chemins (París, 1926). En ella continúa con sus alabanzas a las conquistas picassianas. Lo considera un 
artista inclasificable, pero sin connotaciones negativas aunque comienza a vislumbrarse el pensamiento nacionalista y europeísta con el que acabará identificándose acérrimamente a partir de 1930. Admite que el arte europeo deba regenerarse y elige a Picasso como portavoz de esta evolución bebiendo de mundos orientales, pero sin excederse. Incluso llega a considerar el cubismo como «una forma de expresión antioccidental». Para validar su pensamiento se apoya en la tradición, enumerando a pintores modernos que han hecho lo mismo.

Tras estas dos monografías Ferrer selecciona ocho artículos en los que se muestra claramente la evolución crítica de Waldemar-George que comienza con la reseña del libro de Maurice Raynal de 1921. Ateniéndonos al año en que la realiza podemos hacernos una idea de los derroteros de su pensamiento, aún no tan radicalizado como lo que vendrá después. Aún así, comienza a exigir un código normativo para el cubismo que desarrollará en otros escritos y detecta el núcleo de la creación de Picasso: la representación del objeto per sé, sin tener en cuenta al espectador o los motivos que rodean al objeto dentro del cuadro, es decir, su entorno.

Y con ello llegamos al año 1929, comienzo del viraje ideológico y crítico. Con el artículo «Picasso y la crisis actual de la conciencia artística», Waldemar-George se posiciona en contra de la personalidad revolucionaria del maestro acusándole de crímenes artísticos, pero sin dejar de admirarle por sus obras anteriores como el ciclo de los saltimbanquis o las bañistas. Además se reitera en la idea del valor intrínseco de los objetos representados al detalle.

En abril de 1930 escribe para la revista Formes y en agosto para L'Art Vivant sendos artículos en los que admira el período clásico de Picasso, pero lamenta el rumbo que toma su obra a la que califica de revolucionaria, algo que no acepta. Además, culpa a los seguidores del artista de creer en él ciegamente sin elaborar una opinión juiciosa, hasta tal punto de tachar a Roger Fry de sufrir picassolatría.

Si desde 1921 Waldemar-George ha admirado lo conseguido por Picasso con el cubismo, una década después arremete contra él en su artículo "Los cincuenta años de Picasso y la muerte de la naturaleza muerta». En 1932 con "Aut Caesar aut nihil». Al margen de la exposición de Picasso en las Galerías Georges Petit exalta las obras picassianas anteriores al cataclismo cubista que vendrá. Los personajes de las épocas rosa y azul los sitúa Waldemar-George como herederos de Ribera, Murillo o Velázquez. Esto nos da una idea de la estima que profesaba hacia Picasso antes de la «Supuesta liberación» como él mismo la llama, esto es el año 1907. El cubismo es, según él, la sentencia de muerte del arte europeo, pero los motivos que da para ello no hacen más que reafirmar la genialidad de Picasso, su capacidad creadora e individualista.

En 1946 con dos artículos, los últimos que recoge la presente edición, publicados en la revista Ópera es cuando se reafirma en su nacionalismo denostando el origen español de Picasso con su mirada más allá de los límites europeístas. Por ello no consiente considerar al malagueño representante de la modernidad en Francia pues cree haber ido en contra del humanismo y el naturalismo característicos de los maestros franceses. No debemos pensar que nadie reaccionó en contra de estas ideas. Georges Huisman, muy acertadamente, escribió un artículo en la misma revista (que no se recoge aquí), pero sí la respuesta de Waldemar-George, y por la cual podemos hacernos una idea del contenido.

El origen de todo este cambio ideológico y artístico radica en la concepción personal que poseía Waldemar-George sobre el arte y su utilidad. No creía en la libertad individual, pilar fundamental de la existencia de Picasso, sino en el nuevo humanismo que él mismo fue desarrollando con sus teorías críticas. El Neo-humanismo que llegó a defender el autor estaba basado en el eurocentrismo y la latinización, todo ello orientado bajo el signo de la romanité.

Aunque hayan pasado ocho décadas desde la primigenia publicación en su idioma original, el francés, los textos que aquí se recuperan dan muestra una vez más de las opiniones tan reaccionarias y viscerales que provocaron las creaciones de Picasso. No son más escritos sobre el gran artista del siglo $X X$, sino los escritos salidos de la pluma de un particular crítico cuyo objetivo fue siempre erigirse como defensor acérrimo del arte moderno oficial. No obstante, con sus críticas negativas no hace más que ensalzar las cualidades artísticas de Picasso, su capacidad de aprendizaje y permeabilidad.

En definitiva, a través de esta edición llegamos a Picasso por medio de los ojos de un crítico nada complaciente para con el artista, que buscaba legitimar la idea de un arte al servicio de la nación y bajo lo cual el genial Picasso no cedió.

Por el tratamiento de la figura del artista malagueño, sin condescendencia pero reconociendo su maestría, este 
libro debe ser incorporado a la bibliografía picassiana para los estudiantes y estudiosos ya no solo de Picasso sino del arte del siglo XX en general. Además, podemos considerarlo un manual que por su fisicidad y manejabilidad nos invita a tomar apuntes en los márgenes y destacar las di- versas ideas que de él emanan. Porque como Ferrer titula su prólogo, (la obra de Picasso sigue siendo hoy) Un arte de Anagramas.

Clara Romero Godoy 